\title{
On the integration of digital design and analysis tools
}

\author{
J. Klitgaard ${ }^{1}$, P. H. Kirkegaard ${ }^{2}$ \& M. Mullins ${ }^{1}$ \\ ${ }^{I}$ Department of Architecture \& Design Aalborg University, Denmark \\ ${ }^{2}$ Department of Civil Engineering Aalborg University, Denmark
}

\begin{abstract}
The digital design tools used by architects and engineers today are very useful with respect to their specific fields of aesthetical or technical evaluation. It is not yet possible to fully use the potential of the computer in the design process, as there is no well functioning interplay between the two types of tools. This paper therefore looks at integration of the two types in a prototype for a tool which allows aesthetics evaluation, and at the same time gives the architect instant technical feedback on ideas already in the initial sketching phase.

The aim of the research is to look into integrated digital design and analysis tools in order to find out if it is suited for use by architects and designers or only by specialists and technicians - and if not, then to look at what can be done to make them more available to architects and designers.

The paper contains a case study of three possible approaches for working with digital tectonics by means of acoustics: The architects, the architect-engineer or hybrid practitioner and finally a prototype for a possible digital tectonic tool. For the third approach in the case study, a prototype digital tectonic tool is tested on the design proposal for the auditorium in the planned Utzon Centre in Aalborg, Denmark.
\end{abstract}

Keywords: tectonics, digital tectonics, design tools, Utzon, reverberation time, generative components.

\section{Introduction}

Architects and engineers both employ iterative multi-stage design procedures, starting with initial conceptual design and progressing to more detailed final design. The conceptual design for an architect can be very abstract, with content 
that might be more poetic than geometric. On the other hand the conceptual design for a structural engineer tends to be more tangible in nature, i.e. the choice between an arch and a suspension structure, between concrete and steel [1].

Today different types of digital design and analysis tools exist which can support architects as well as engineers during the design process. An integration of these design and tools would allow the engineer to take full advantage of the opportunities provided by the architecture, at different levels of refinement, by directly deriving structural schemes from the 3D model. It also allows the architect to receive more opportune and informed structural feedback, and to detect structural problems earlier in the process. At the core of this approach lies a design representation that describes relevant information to both disciplines in a uniform framework and reflects the strong interdependency between the architecture and the structure.

An area in architecture where aesthetics and structure are interconnected is within tectonics. With the word "Tecton" meaning a carpenter or builder, and the "Archi-Tecton" meaning a master-builder [2], then the possibilities for a contemporary translation of tectonics could be very wide.

The definition used in this article is the one, where the goal in tectonics is to use materials in accordance with their physical properties, and the design of an honest displayed construction [3].

Roughly building design can be viewed as a process where the architect formulates the guides within which then the engineer designs the construction. This causes a linear work flow in the process, and once engineers have started projecting the building it will be very costly to go back into modifying the overall building shape, if something would show to be disadvantageous in the design - e.g. an unwanted acoustical environment. These things should not happen in tectonic design where technical considerations are integrated in the initial sketches.

Tectonic design being construction design on one hand contains a lot of thoughts on statical, acoustical and other functional parameters. It also has to fulfil the aesthetical demands from the architect. Therefore it is advantageous for the process that the architect has knowledge of both technical and aesthetic aspects and uses them already in the early design phase.

\subsection{Digital tectonic tools}

In the world of modern architecture computers are - apart from managing and controlling the building process - mainly used for two purposes. That is to make virtual representations of spaces or for photorealistic renderings [4]. The first is mainly to investigate and form and to describe complex shapes that would have been difficult, if not impossible to describe in 2D planar drawings. Renderings are also mostly used for investigating or presenting a design visually.

One way of moving tectonic design forward in modern architecture is to use the potential given by various computer programmes, which are available today. Various computer programmes are used in the design of buildings, but as it is today there is often a separation between the tools used for generating the shape 
and the tools used for e.g. verifying the statics or acoustics etc. of a building. The problem is that this part of the design process is carried out by other people than the architect, which maintains a status quo for the integration of computer tools in the process, as the understanding is with someone else than the architect.

The range of tools is wide, where on the one hand the architect can turn towards programmes primarily made for visualising and illustration of conceptual ideas, or on the other hand to the other extreme of numeric calculation tools for designing optimal solutions, originating from civil engineering. With the development of computer tools for e.g. structural optimization it is possible for an architect with statical know-how, to use these programmes as the design driver [5].

To be able to use the tools, which are mainly developed within the field of civil engineering, it is necessary to have a fundamental understanding of the technical areas in play. The programmes existing today are mainly designed for engineers and technicians and are used for verification of the building some time after the initial sketches are developed by the architect. These computer programmes are available for simulating e.g. the physical properties of a construction or acoustical environment, which would be of great use for architects to be able to influence in order to develop their designs.

A new generation of computer tools for architectural design should provide the possibility for the architect to work with both the aesthetic as well as the technical aspects of architecture.

The aim of this research is to look into integrated digital design and analysis tools in order to find out if it is suited for use by architects and designers or only by specialists and technicians - and if not, then to look at what can be done to make them more available to architects and designers.

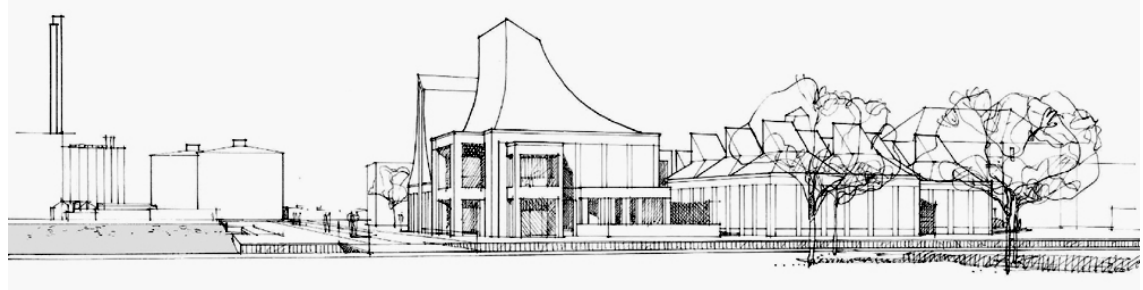

Figure 1: $\quad$ Sketch of the Utzon Centre Aalborg.

For the case study of the various design approaches the roof structure over the $240 \mathrm{~m}^{2}$ auditorium in the Utzon Centre in Aalborg, Denmark, is used as basis. More precisely the case study looks at different approaches for shaping the roof acoustically.

Three different approaches will be presented in the following section. The first is the typical architects approach. The second is the approach of the architect-engineer or hybrid-practitioner, and after a short evaluation of the two approaches a third approach, which describes a prototype for a digital tectonic tool. 


\section{Possible design approaches}

If an architect would design the roof structure all over again, what are then his possibilities? Roughly there are, as we see it, three different approaches to the design of an acoustical roof shape:

\subsection{The architects approach}

The first one, which is the geometric acoustical way to do it for an architect with some acoustic knowledge, and also a technique which Jørn Utzon is known to use, is to do a sketch of the desired curvature, and then, by drawing lines, projecting sound, onto the surface and then under the assumption that the angle of incidence equals the angle of reflection, to design a assumed diffuse sound field.

This approach is quite useful for architects and does not require any tools apart from paper and pen. A small amount of knowledge about acoustical design is required, but only what an architect would be assumed to know. The method is simple and does not require help from an acoustics expert. Therefore it is very useful in the early sketching phase, as new sketches for shaping the roof, can easily be investigated at a low consumption of man-hours.

In any design process the testing of a large number of sketches may be required to get the right aesthetic solution, and the approach above is suited for this design process.

What probably happens once the architect feels that he has reached a desirable design is that the drawings are then handed over to an engineer, who calculates reverberation times for the room or makes an auralization - a simulation of the acoustical environment, to verify that the room fulfils the desired requirements.

The final adjustments of the design might in this case end up being made by an engineer, who might not make the same aesthetical considerations as the architect, fig. 2 (a). One problem in relation to this step in the process is that once the engineer is involved, then costs go up because of the man-hours spent. This problem is what sometimes causes struggle between the architects and engineers, when the architect does not approve of the modifications, and wants to do a new iteration on the design.

\subsection{The hybrid practitioner approach}

The second approach is one which falls within the definition "Digital Tectonics" as it is described by Neil Leach et al in the book with that exact same title, where an architect-engineer or hybrid practitioner works simultaneously with both aesthetic and technical, in this case acoustic, design requirements [6].

With "tectonics" understood as structural or in this case acoustical parameters in play as design drivers rather than detaching them from the architectural design process. "Digital" as it is dependent on the digital tools available on the market. These digital tools are programmes like CATT [7] and ODEON [8], which can calculate reverberation times and do auralization [9]. 
This kind of tools requires a substantial acoustical knowledge, in order to be able to use them in the initial sketching phase.

When that knowledge is present the architect will be able to take the results the reverberation times and the auralization, from the programmes into consideration before the drawings are sent to the engineers for verification, if that is even necessary. The results from the architect's calculations are likely to be as accurate as the ones that an engineer would come up with, as the tools he would be using are the same.

This accuracy is on the other hand also the problem of this working approach. Every time the architect wants to do an iteration on the design, then he will have to draw a new sketch, likely by hand, build or modify a 3D CAD model of the room, import it into the programme and prepare if for calculation inside the acoustical simulation programme, before he can get the feedback that he needs to evaluate the acoustical properties of the design [10].

As the input for these programmes has to be very accurate in order to give the correct result, then this work process of doing an iteration is a slow way of developing a design. Therefore it might not be so suited for the initial sketching process [11].

The problem is that the interaction with the geometry of the design is done in $\mathrm{CAD}$, and the acoustical feed back which causes the architect to alter the design comes from a different programme, fig. 2 (b). Going from one programme to the other is very time consuming, and it is not a good way of testing a couple of ideas in a hurry.

\section{Architect digital design tools $\rightarrow$ Engineer digital analysis tools \\ Architect digital design tools $\rightleftarrows$ digital analysis tools $\rightarrow$ Engineer \\ Architect digital design tools digital analysis tools \\ Engineer}

Figure 2: $\quad$ The three approaches - (a) the architects, (b) the hybrid practitioner and (c) the approach provided by the prototype, showing the initial sketching phase on the left side of the black arrow and the detailing phase on the right side.

\subsection{Problem identification}

The two previously described cases reveals that both the architect and hybrid practitioner cannot use the potential of the computer in the early design process.

For the architect to be able to use the computer programmes, they will have to contain an embedded knowledge that the architect can benefit from, perhaps without knowing all the theory behind the various calculations in the computer programme. 
For the hybrid practitioner who knows about the, in this case, acoustic theory, the interesting next step would be to provide a tool, in which he could change an amount of desired design variables, without having to start from scratch with the CAD model every time that the design changes, so that the flow in the sketching process is not interrupted, as it is important to be able to iterate quickly in the early sketching phase [12].

The ideal tool for the sketching process would therefore be one, in which the geometry of the model could easily be manipulated and provide the acoustical feedback real time, fig. 2 (c).

\section{The Utzon Centre in Aalborg}

The Utzon Centre on the harbour front of Aalborg is designed by Jørn Utzon and his two sons, Kim and Jan Utzon, and it is going to function as a cultural institution, where architects, student and others can meet or hold conferences.

The centre also contains a library and archives with most of Jørn Utzons sketches from his office.

Jørn Utzon, who is best known for the Sydney Opera House, is as an architect very concerned with creating quality for the users, in the buildings he designs.

This humanistic approach is reflected in design of the centre and in the modest scale of it.

The desire to make a good environment for the users is also reflected in the way Utzon works with natural lighting and acoustics in his buildings. These matters are treated with great attention and with Utzon, as many other architects in the modern movement, underline the relation where form is derived from its function [13].

"It's the construction I am interested in... I want to expose it. That is something that I have learnt from nature."

Jørn Utzon

The Utzon Centre is an example of Jørn Utzon's concepts for additive architecture, which he developed as far back as in the 1960s, where he made a proposal for the Export College in Herning, Denmark, in a very similar way.

The design, with its many cubes and varying roof shapes is very much inspired by Utzon's studies of Arabian bazaars; the various roof shapes derive from the demands from the functions below them, regarding light and volume [14].

Three distinct roof structures are seen on the building. One is over the library, another over the workshops and the last on over the auditorium. This article focuses on the design of the roof structures over the auditorium.

"... and there is an acoustically shaped roof, which rises high above the seat, and then you have a number of large niches that you look out through, which frame a picture for each seat, of the fjord..." 


\subsection{The new digital tectonic approach}

The third design process approach in the case study is an initial proposal for a prototype for a digital tectonic tool developed in the computer programme 'Generative Components' [15]. It is a good basis for a prototype for such a digital design tool, as it can provide real time feedback to the architect, when the design is modified.

The aim with the prototype is to investigate the possibility to use 'Generative Components' as digital tectonics tool which could be useful in an early design phase by allowing the architect to manipulate the shape of the roof structure - In this case the auditorium in the Utzon Centre - and at the same time give the architect real time feedback on the reverberation time and the visual looks of the room.

The prototype is able calculate the reverberation time using Sabine's formula:

$$
T_{\text {Sabine }}=55,3 \cdot \frac{V}{c \cdot A}
$$

where $T_{\text {Sabine }}$ is the reverberation time [s], $V$ is the Volume of the room $\left[\mathrm{m}^{2}\right], c$ is the sonic speed of sound at $21^{\circ} \mathrm{C}[\mathrm{m} / \mathrm{s}]$ and $A$ is the area of the surface multiplied by the absorption coefficient of the material of the surface $\left[\mathrm{m}^{2}\right]$.

For an auditorium to be a good acoustic environment for speech, then the reverberation time should to be around 1.0 to 1.3 in the $500 \mathrm{~Hz}$ band.

'Generative Components' is a parametric design tool which has uses in many areas other than acoustic design, but the programme was chosen as it facilitated a good possibility for interaction with external computer programmes compared with conventional design tools like Rhino.

The design of the geometry in the prototype is very determining for which parameters the architect wants to be able to manipulate. These variables must be chosen before building the geometry. Otherwise too radical changes to the geometry may corrupt the 'TransactionFile' which keeps track of relation between different parts of the geometry. It would therefore be likely that a complete rebuild of the geometry could be necessary if new design variables are necessary. Dependent on the complexity this might be a time consuming task which suggests that initial sketching with pen and paper would be appropriate before 'tuning' the design in the 'Generative Components' model.

This prototype allows the user to change the curvature of the roof with two variables, which are setup in 'Generative Components' as sliders that control the midpoint of the $B$-spline curves which delimit the roof.

The prototype provides the desired feedback for the architect and works without any problems. When changes are made in geometry in the CAD programme, then the reverberation time is updated real time in the spread sheet, where the calculations are made.

The combination of visual feedback of the shape in combination with acoustical feedback in the way of reverberation time is a good combination for tuning a design before it is handed over to the engineers for final projecting. 


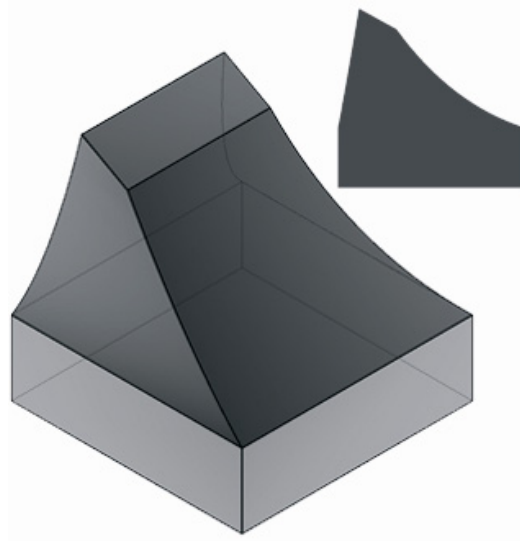

TSabine $(500 \mathrm{~Hz})=1.304 \mathrm{~s}$

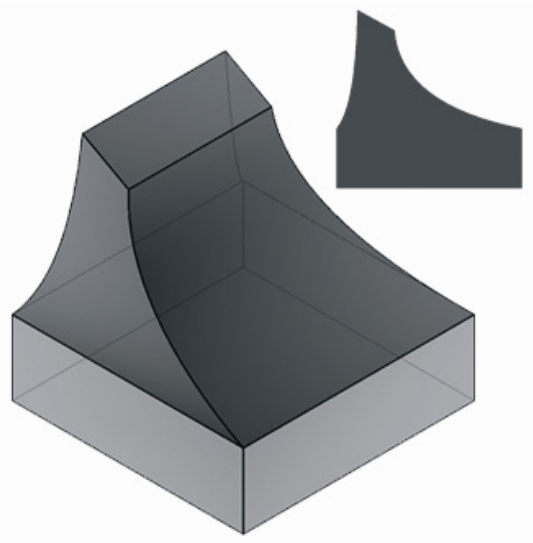

TSabine $(500 \mathrm{~Hz})=1.198 \mathrm{~s}$

Figure 3: $\quad$ Examples of geometry and reverberation time from the prototype.

The prototype is suited for simple acoustical considerations, but far from as sophisticated as acoustical simulation programmes. Also, because of the specific focus on the Utzon Centre roof structure, the geometry is very specific for this one project. To do other projects the prototype will have to be rebuilt. As this is a time consuming and not suited for initial sketching, with the exception of cubical rooms for which a general prototype could quite easily be build. The only design variables needed would be the length, width and height of the room and the damping coefficient of the materials of the various surfaces.

The choice of materials is made with different approaches, depending on whether you are an acoustics engineer or you are an architect. Where an acoustics engineer would choose materials with the aim to make a good acoustic environment he might not consider the same qualities in materials as an architect, who would look for the right colour, tactility, texture, reflectivity, transparency etc.

On the other hand an architect would perhaps not be looking for materials with the right acoustical properties as a primary objective. If these properties were embedded in the CAD-program, then the architect would have what could be called 'extended' knowledge, which would be available when designing a room.

With the prototype an architect would be able to test materials and know the reverberation time of the room, without having to consult the engineer for this.

\section{Conclusion}

In this paper three possible approaches to tectonic architectural design are discussed. With the computer technology available an integration of design and analysis tools could give the architect a possibility to get instant feedback on ideas already in the initial sketching phase. 
The three approaches show, that both the architect and hybrid practitioner cannot yet use the full potential of the computer in the design process. That is because the existing computer programmes are developed to sustain the work of either the architect or the engineer. The interaction between the two types is so far not working seamlessly.

A programme which could sustain the work of the architect without having to involve a technician in the early design phase seems to be desirable. The program should contain an embedded knowledge which the architect can benefit from, regardless if he knows all the theory behind the programme.

A hybrid practitioner, who already knows the theory, stands to gain speed by the tools, as the design iterations can be done instantly and provide real time feedback.

The new digital approach prototype is fitted only for the given geometry, and more general tools are still to be developed. Before they do it is up to the architect or any other user of the programmes to build them. The role of the architect is then to describe beforehand, the design parameters that he or she wants to be able to manipulate. In that way, he or she stands to gain, for the particular case, a very usable tectonic tool. This kind of 'extended' knowledge could also sustain the cognition of various physical behaviours, if the prototype was used for educational purposes.

Concerning the results from the prototype it should be stated, that the reverberation time is only a function of volume, surfaces and damping coefficients. Other parameters like distribution of sound are not regarded in this case study. Also, if instead of doing the Utzon Centre auditorium had done simple a square room, with variable height, width, length and surface materials, one would have a tool that could find a more general use.

\section{References}

[1] Mullins, M., Kirkegaard, P.H., Jessen, R. Z. \& Klitgaard, J., A Topology Optimization Approach to Learning in Architectural Design, Proc. Of the $23^{\text {rd }}$ eCAADe Conf. on Digital Design, eds. J.P. Duarte, G. Ducla-Soares and A.Z. Sampaio, Dossier, Lisbon, pp. 155-162, 2005.

[2] Frampton, K. \& Cava, J. (eds.), Studies in Tectonic Culture - The poetics of construction in the Nineteenth and twentieth century, MIT Press, Cambridge, Third Printing; 2001.

[3] Schmidt, A.M.D., Digital Tectonic Tools, Proc. Of the $23^{\text {rd }}$ eCAADe Conf. on Digital Design, eds. J.P. Duarte, G. Ducla-Soares and A.Z. Sampaio, Dossier, Lisbon, pp. 657-664, 2005.

[4] Jabi, W., Digital Tectonics: the intersection of the physical and the virtual, Proc. Of the 2004 Conf. of the AIA Technology in Architectural Practice Knowledge Community, eds. S. Williamson, P. Beesley and N. Cheng, ACADIA, Cambridge (Ontario), pp. 256-269, 2004.

[5] Frier, C. and Kirkegaard, P.H., Tectonic design of concrete panels by means of topology optimization techniques and limit state analysis Proc. of the $12^{\text {th }}$ IFIPWG 7.5 Working Conf. on Reliability and Optimization of 
Structural Systems, eds. D.M. Frangopol, J. Dalsgaard, Balkema, Aalborg, 2005

[6] Leach, N. (eds.), Williams, C. (eds.), and Turnbull, D. (eds.), Digital Tectonics, Wiley, Chichester, 2004.

[7] CATT: http://www.catt.se/CATT-acoustics.htm

[8] ODEON: http://www.dat.dtu.dk/odeon/

[9] Jørgensen, K.H., Kirkegaard, P. \& Andersen, L. An Optimization Approach for Room Acoustics Design, Dept. of Civil Engineering, Aalborg University, Denmark

[10] Andersson, I. K., Digital Tectonics - Values and Methods in Architecture, 2005, Dept. of Architecture and Design, Aalborg University, Aalborg, Denmark.

[11] Kouzeleas, S.T, Definition of a Method of Limits of the Simplification of a Hall Model in a CAD System to Diminish Falsification of Acoustic Simulation Results, Proc. Of the $23^{\text {rd }}$ eCAADe Conf. on Digital Design, eds. J.P. Duarte, G. Ducla-Soares and A.Z. Sampaio, Dossier, Lisbon, pp. 695-704, 2005.

[12] Szalapaj, P., The Digital Design Process in Contemporary Architectural Practice, Proc. Of the $23^{\text {rd }}$ eCAADe Conf. on Digital Design, eds. J.P. Duarte, G. Ducla-Soares and A. Z. Sampaio, Dossier, Lisbon, pp. 751-759, 2005.

[13] Møller, H.S., Udsen, V., Nagel, P. Jørn Utzon Houses, Living Architecture, Copenhagen, 2004.

[14] Dirckinck-Holmfeld, K. and Keiding, M., Utzon and the new tradition, The Danish Architectural Press; Copenhagen, 2005.

[15] Generative Components: http://www.bentley.com/en-US/Markets/ Building/GenerativeComponents.htm 